\title{
Correlation Analysis of Service Quality Gaps in a Four-Star Hotel
}

\section{in Iran}

\author{
Arash Shahin (Corresponding author) \\ Department of Management, University of Isfahan, Isfahan, Iran \\ 1.242 Saeb Avenue, 81848-13713, Isfahan, Iran
}

Tel: 98-311-793-2040 E-mail: arashshahin@hotmail.com

Reza Dabestani

Department of Management, University of Isfahan, Isfahan, Iran

24, Shaghayegh Sharghi Block, Kowsar residential complex, 5th alley, Golestan Street

Kaveh Avenue, Isfahan, Iran

Tel: 98-311-793-2040Ｅ-mail: reza.dabestani@gmail.com

\begin{abstract}
During the past decades, service sector has been known as an important player in the world economy. Considering the significant role of services in the hospitality industry, this research assesses the service quality gaps based on expectations and perceptions of customers in a four-star hotel in Isfahan as the major tourism focal point in Iran. For this purpose, service quality gaps have been measured and studied through correlation analysis based on a comprehensive set of service quality dimensions. The findings imply that almost all of the service quality gaps are positive and "price" as a service quality dimension has the highest positive value. "Communication" also has the highest correlation with other service quality dimensions.
\end{abstract}

Keywords: Service Quality, Hotel, Dimension, Gaps Correlation

\section{Introduction}

Service quality is crucial to the success of any service organization. Since customers participate in delivery and consumption of services, they interact closely with various aspects of organizations. This knowledge gives them the opportunity to assess critically the services provided in organizations (Kandampully, 2000). Customers will assess service quality by comparing services they received with their desired services. Hence, service quality plays a critical role in adding value to the overall service experience (Lau et al, 2005).

During the past decades, the tourism industry has become one of the most important players of economies worldwide. This important industry has many infrastructures and service institutions in its category among which the most important infrastructure is the hotel industry. In this respect, customer satisfaction is a definite need for service organization improvement and therefore, maintaining and measuring customer satisfaction, as one of the most important aspects of quality improvement is a basic need of organizations. King (1995) mentioned that hospitality as a commercial activity is a special kind of relationship between service providers and customers. In this relationship, the host understands the needs and wants of the customer and gives pleasure to the customers in order that they enhance their needs and feel comfortable. The hospitality industry simply cannot survive without delivering satisfied quality of their services. Based on academic literature, Wuest (2001) reported similar impacts of service quality in tourism, hospitality, and leisure businesses which were improving guest convenience; enhancing service provider's image; ensuring customer security; generating traffic linking to profits, saving costs, and higher market share; and establishing a competitive edge, and customer demand.

For the attempts of the hospitality industry to attain service quality as sustainable competitive advantage, researchers affirmed that hospitality organizations are actively receptive to service quality initiatives, such as the British Standards Institute, the European Quality Award, the Malcolm Baldrige National Quality Award, and the Edwards Deming prize. In addition, the hospitality organizations pay close attention to raising service quality through investment in human resources development (Narangajavana, 2007).

In this paper, the hospitality industry and in particular the hotel sector is undertaken for correlation analysis of service quality gaps. It is important to note that while the literature review denotes that a large and relatively similar work has been done on the SERVQUAL approach and the correlation analysis of the dimensions values, 
there seems a lack of work on the correlation analysis of service quality gaps. Therefore in the following, the literature is reviewed on the subject of service quality, its dimensions and gaps. Then, the new methodology is described and a four-star hotel in Isfahan as the major zone of tourism in Iran is undertaken as a sample for analysis. A comprehensive set of service quality dimensions (SQDs) which encompasses all the aspect of delivered services is used for analysis. The correlation and gap analysis is used to find the interrelationships amongst SQDs and to prioritize the addressed dimensions. Finally, the results are analyzed, discussed and major conclusions are presented.

\section{Literature review}

A service is an activity or series of activities of more or less intangible nature that normally, but not necessarily, take place in interactions between customers and service employees and/or physical resources or goods and/or systems of the service provider, which are provided as solutions to customer problems (Fitzsimmons and Fitzsimmons, 2000). The subject of service quality is wide and varied. The theory has been greatly developed by many researchers. During the past decades, many scholars have recognized and investigated the subject of service quality. In numerous service quality resources, conceptualization, measurement, implementation, and management of service quality have been studied. The concept of service quality was established after there had been a growing interest in the quality of goods served. Garvin (1988) was among first scholars who examined the quality concepts to cover both goods and services. He explained perceived quality as the subjective perception of quality through indirect measures of quality comparison. Christopher (1994) introduced perceived service quality as a result of comparing the real experience with the expectation of a customer before consuming the service. Based on the perceived service quality concept, Parasuraman et al. (1985) applied premises from other previous studies to form their model of service quality gaps. The ideas included a consumer had difficulty in evaluating service quality rather than goods quality, that a perception of service quality was developed from a comparison of consumer expectation with actual service performance; also quality evaluation involved the evaluation of both the process and outcome of service delivery. Therefore, service quality gap denotes the gap between customer's expectations (E) or what the service should provide and the customer's perception $(\mathrm{P})$ of what the service actually provides (Shahin, 2006):

$\mathrm{G}=\mathrm{E}-\mathrm{P}$

In the conceptual model of Parasuraman et al. (1985), 10 quality dimensions were introduced which included reliability, responsiveness, competence, access, courtesy, communication, creditability, security, understanding/knowing the customer, and tangibles. Parasuraman et al. (1988) developed a multiple-item scale (SERVQUAL) for measuring service quality and simplified the 10 dimensions of service quality to five dimensions as tangible, reliability, responsiveness, assurance and empathy. In this paper, a comprehensive set of 12 SQDs is considered for the study as addressed in Table 1.

While Parasuraman et al. (1988) identified five gaps that can result in unsuccessful service delivery, the majority of literature has focused on the fifth gap, which is the difference between customer's expectation and perception of service quality. The studies are not limited to five gaps as Luk and Layton (2002) and Shahin et al. (2006) addressed more gaps.

The outcomes of studies on service quality addressed several contributions to dimensional structure of service quality in the hospitality industry. These studies have argued that in the hotel sector, some of quality dimensions are different from the five dimensions described by the original SERVQUAL researchers. Akan (1995) developed a questionnaire adapted from the SERVQUAL instrument and investigated the application of the SERVQUAL instrument in an international environment. Akan aimed to examine the dimensions of the SERVQUAL and measure the level of importance of the dimensions for the users of four and five star hotels in Turkey. He identified seven dimensions including courtesy and competence of the personnel, communication and transactions, tangibles, knowing and understanding the customer, accuracy and speed of service, solutions to problems, and accuracy of hotel reservations among which, courtesy and competence of hotel personnel were the most significant dimensions influencing the perception of quality.

Enz and Siguaw (2000) examined the best practices in service quality among the US hospitality industry. Only a small number of hotel operations focused specifically on service excellence, which they did extremely well for one or more service issues; creating a service culture; building an empowered service-delivery system; facilitating a customer listening orientation; and developing responsive service guarantees.

In the field of hospitality, the measurement of service quality was derived from the concept and studies of service quality experts. A number of studies applied or modified the SERVQUAL instrument to measure service quality in the hospitality industry. Several specific instruments were developed based on the SERVQUAL approach. Lee 
and Hing (1995) supported the SERVQUAL application in measuring service quality because it was relatively simple and inexpensive; provided benefits to entrepreneurs for developing better tailored marketing; and was comparable in tracking the service quality of different firms in the same business sector.

The study of Saleh and Ryan (1992) attempted to apply the SERVQUAL approach within the hospitality industry. Initially, assuming the same five dimensions of the developers, the result of their study however showed a somewhat different construct from the original approach of the SERVQUAL. The factor analysis of the study combined tangibles, reliability, responsiveness, and assurance dimensions of the original approach into "conviviality", the first factor of Saleh and Ryan's study, which explained roughly $63 \%$ and the remaining four factors (tangibles, reassurance, avoid sarcasm, and empathy) accounted for another $16 \%$. They justified that different constructs might occur when using a 5-point scale instead of a 7-point scale as in the original research, and the invalidity of questions concerning tangibles.

Mei et al. (1999) examined the dimensions of service quality in hotel industry in Australia. They used the SERVQUAL approach as a foundation and developed a new scale called HOLSERV scale as a new instrument to measure service quality in the hotel industry. They concluded that service quality could be represented by three dimensions in the hotel industry as employees, tangibles, and reliability. Fick and Ritchie (1991) examined the SERVQUAL approach and its management implications in four major sectors of travel and tourism industry, i.e. airline, hotel, restaurant, and ski area services. They found that the most important expectations concerning service are reliability and assurance for all of the four sectors.

As it was emphasized earlier and is clear from the literature review, while there a large and relatively similar published work exists on the SERVQUAL approach and the correlation analysis of the dimensions values, there seems a lack of work on the correlation analysis of service quality gaps.

\section{Research methodology}

Hotels play a vital role in improving tourism in Iran and contribute to remarkable economic growth in historical cities such as Isfahan. A survey is developed and conducted in a four star hotel in Isfahan as the major tourism focal point in Iran.

The data is collected using 30 questions, based on the second level of SQDs in Table 1, which are submitted to customers in order to measure their perceptions and expectations. Therefore, customers are asked to response to totally 60 questions. Customers are also asked to fill the questionnaire using a five point Likert scale ( 1 as very low, 2 as low, 3 as moderate, 4 as high and 5 as very high).

As it is addressed in Table 1, the questionnaire includes four questions related to reliability, three questions to responsiveness, three questions to security and confidentiality, two questions to access and approachability, two questions to communication, two questions to understanding the customer, three questions to credibility, three questions to tangibles, two questions to courtesy, two questions to price, two questions to competence and two questions to flexibility.

\section{Sample selection and data collection}

Aseman Hotel is selected for the survey. The Aseman hotel is located in the heart of the historical city of Isfahan. It's only 20 minutes away from the Isfahan International Airport and 5 minutes away from the Isfahan city center. Hotel Building is a one block with 13 floors, each of which has at least two guests elevators for optimum convenience. Aseman Hotel offers 90 rooms with five single, 30 double and twin, 35 triple, 15 standard suites and four royal suites and one suit conference.

The sample of the survey includes 38 customers of the hotel. Table 2 addresses the demographic characteristics of the sample of customers. As it is clear, majority of the sample of respondents contains young people $(71.1 \%$ less than 35 years old). In this category, $15.8 \%$ of respondents are between 15 and 25 years old and $55.3 \%$ are between 25 and 35 years old. $68.4 \%$ of customers are men and $31.6 \%$ are women. Most of the customers (50\%) have bachelor degree and $74.4 \%$ earn more than five million Rials per month. $31.6 \%$ of respondents are single, while $68.4 \%$ of them are married. $32 \%$ of respondents have experienced the hotel more than two times.

\section{Findings and discussion}

The values in Table 3 denote the gaps of SQDs and as it is depicted, all of the values are positive. These positive values indicate that the delivered service performance is lower than customers' expectations. The "Price" gap has the highest positive value amongst the SQDs. The lowest positive value is also related to creditability. The reliability of data is calculated by the Cronbach's Alpha with the value of 0.833 which is satisfactory.

The Pearson correlation test is also performed on the data and the results are presented in Table 4. As it is shown 
in Table 4, while there are correlations amongst a number of the SQDs, the significant correlations are just related to a few of the dimensions.

The 1 to 12 codes on the first row of the Table, refer to SQDs which are represented on the second column. With the same order, as it is illustrated, communication has the highest correlation with other SQDs. Also, there are significant correlations among other service dimensions including flexibility, competence, responsiveness, understanding the customers, tangibles, courtesy and creditability. The SQDs which do not have significant correlations are reliability, security and confidentiality, access and approachability and price. If we assume that values higher than 0.5 denote a relatively strong correlation, then it is argued that the highest correlation value of 0.60 is also referred to communication and courtesy.

As it was addressed in Table 3, some of the standard deviations were relatively high. For example, the value of standard deviation of "price" dimension is almost 1 which is very high. It is important to note that the gaps can have a maximum value of 4 , and therefore, the gap value of this dimension (i.e. 1.1447) should be considered with more care.

The advantage of this research, comparing to the literature (e.g. Akan, 1995 and Mei, 1999) is in undertaking correlations amongst service quality gaps. The proposed approach could be used in any service organization and it is believed that the findings could provide great competitive advantage to hotel managers who try to improve their customer satisfaction.

However, regarding the fact that there are some correlations amongst service quality gaps in this research, it is likely to have correlations amongst SQDs, similar to what is apparent in the literature. Similar to the investigation of Saleh and Ryan (1992), the proposed approach of this paper could be developed for factor analysis in order to reduce the number of dimensions and recategorize them. The difference would be that Saleh and Ryan made the factor analysis on the dimensions values and the new approach suggests the analysis to be made on the gaps values.

Another important subject, which is necessary to explain is that the 12 dimensions used in this study seems comprehensive compared to other studies addressed in the literature as it encompasses almost all the dimensions used by other researchers.

The gap analysis is critical and valuable from the view point of the hotel managers because it is a useful tool for them to identify the service problems or service fail points. It is recommended to the hotel mangers to carry the proposed anlysis regularly so that they can understand more about the customers' evaluation process, and thus meet customers' expectations more consistently.

Another managerial implication includes the need for the hotel to develop human resource management strategies to train employees to become more skilled in their job, have excellent communication skills, being courteous, friendly and competent to meet customers' need. This aspect of the study is compatible with the Nadiri and Hussain (2005) investigation. Considering the correlation of the gap of tangibles with other gaps, it is suggested to the hotel managers to invest in hotel decor including appearance, tools and equipment used to provide service and physical facilities. This is in consistence with the findings of Wong et al. (1999) and Lau et al. (2005). As underlined by Zeithaml and Bitner (2003), in the hospitality industry where customers visit the establishment to receive the services, the tangibles should be overemphasized.

\section{Conclusions}

In this paper, service quality gaps were examined using correlation analysis. A comprehensive set of SQDs which encompasses almost all of the aspect of delivered services was used for analysis. The findings imply that all of the service quality gaps were positive and price as a service quality dimension had the highest positive value. Communication had also the highest correlation with courtesy. In addition, this dimension had the most interrelationships with other SQDs including responsiveness, creditability, courtesy and flexibility.

Compared to other studies, this paper also has some limitations. Although the set of SQDs used in this research seems comprehensive, it is costly and time consuming due to the large number of questions it holds. As a suggestion, factor analysis prior to the correlation of gaps might be an effective solution. With respect to similar investigations which are survey based and conceptual, the same problems exist and sometimes the quality of data is questionable. For this purpose, increasing the sample size will increase the quality of the data.

In this study, it is assumed that all the gap values of SQDs dimensions have the same importance value. However, in real cases, their importance might not be equal. On the other hand, the results are limited to one hotel and cannot be expanded to other hotels and service providers of the hospitality industry. These two important issues provide good opportunities for further development of the subject in future studies. 
In this paper, only the correlation analysis was made on the service quality gaps. The next subject of research that the authors are currently studying is the comparison between the results of correlation analysis of dimensions and the results of the correlation analysis of gaps. If the results become different, then it would mean that relying on only the results of the correlation analysis of dimensions values is risky and insufficient and service organizations should no longer utilize the simple traditional approaches commonly used in the literature.

\section{References}

Akan, P. (1995). Dimensions of service quality: a study in Istanbul. Managing Service Quality, 5(6), 39-43.

Christopher, W.F. (1994). The Service Quality Handbook. New York: AMACOM.

Enz, C.A. \& Siguaw, J.A. (2000). Best practices in service quality. Cornell Hotel \& Restaurant Administration Quarterly, 41(5), 20-29.

Fick, G.R. \& Ritchie, J.R. (1991). Measuring service quality in the travel and tourism industry. Journal of Travel Research, 30(2), 2-9.

Fitzsimmons, J.A. \& Fitzsimmons, M.J. (2000). Service management: Operations, strategy, and information technology. Singapore: Mc Graw-Hill.

Garvin, D. A. (1988). Managing Quality: The Strategic and Competitive Edge. New York: The Free Press.

Kandampully, J. (2000). The Impact of Demand Fluctuation on the Quality of Service: a Tourism Industry Example. Managing service Quality, 10(1), 10-18.

King, C.A. (1995). Viewpoint: What is Hospitality?. International Journal of hospitality Management, 14(3/4), 219-234.

Lau, P.M., Khatibi, A.A. \& Fie, D.Y.G. (2005). Service Quality: A Study of the Luxury Hotels in Malaysia. Journal of American Academy of Business, Cambridge, 7(2), 46-55.

Lee, Y.L. \& Hing, N. (1995). Measuring quality in restaurant operations: an application of the SERVQUAL instrument. International Journal of Hospitality Management, 14(3/4), 293-310.

Luk, Sh.T.K. \& Layton, R. (2002). Perception Gaps in customer expectations: Managers versus service providers and customers. The Service Industries Journal, 22(2), 109-128.

Mei, A.W.O., Dean, A.M. \& White, C.J. (1999). Analyzing service quality in the hospitality industry. Managing Service Quality, 9(2), 136-143.

Nadiri, H. \& Hussain, K. (2005). Perceptions of Service Quality in North Cyprus Hotels. International Journal of Contemporary Hospitality Management, 17(6), 469-480.

Narangajavana, Y. (2007). The Relationship of hotel Rating system and Service Quality, a Case Study of the Thailand Hotel Standards. Doctoral Thesis, Oklahama: Oklahama State University.

Parasuraman, A., Zeithaml, V.A. \& Berry, L.L. (1985). A conceptual model of service quality and its implications for future research. Journal of Marketing, 49(4), 41-50.

Parasuraman, A., Zeithaml, V.A. \& Berry, L.L. (1988). SERVQUAL: A multiple item scales for measuring consumer perceptions of service quality. Journal of Retailing, 64(1), 13-40.

Saleh, F. \& Ryan, C. (1992). Analyzing service quality in the hospitality industry using the SERVQUAL model. The Service Industries Journal, 11(3), 324-343.

Shahin, A. (2006). SERVQUAL and model of service quality gaps: A framework for determining and prioritizing critical factors in delivering quality services. In: Service quality - An introduction. Partha Sarathy V. (Ed.). Andhra Pradesh: ICFAI University Press, 117-131.

Shahin, A. (2007). In-Flight Service Quality Dimensions: A Comprehensive Review. International Journal of Excellence in Tourism, Hospitality \& Catering, 1(2), 13-27.

Shahin, A., Dehghan, A. \& Albadvi, A. (2006), Service Quality Gaps and Six Sigma with a Case Study on CCG (Customer Centric Group). Proceedings of the Second International Conference on Six Sigma, Glasgow, 50-64.

Wong, O.M.A., Dean, A.M. \& White, C.J. (1999). Analysing Service Quality in the hospitality Industry. Managing Service Quality, 9(2), 136-143.

Wuest, B.S. (2001). Service quality concepts and dimensions pertinent to tourism, hospitality, and leisure services. In J. Kandampully, C. Mok, \& B. Sparks (Eds.). Service Quality Management in Hospitality, Tourism, and Leisure (pp. 51-66). New York: Haworth Press. 
Zeitaml, V.A. \& Bitner, M.J. (2003). Service Marketing: Integrating Customer Focus across the Firm. New York, NY: McGraw-Hill.

Table 1. 12 service quality dimensions in two levels (Shahin, 2007)

\begin{tabular}{ll}
\hline First level & Second level \\
\hline (1) Reliability & (1) Performance \\
& (2) Accuracy and Dependability \\
& (3) Consistency \\
& (4) Completeness \\
& (1) Willingness to help customer \\
& (2) Readiness, Promptness (Timeliness and speed) \\
(2) Comfort & (1) Physical security \\
(3) Security and & (3) Sinancial security \\
confidentiality & (1) Ease of contact \\
(4) Access and & (2) Timely access \\
approachability & (1) Word-of-mouth communication \\
(5) Communication & (2) Giving information \\
(1) Comprehension \\
(2) Understanding the & (1) Trustworthiness and Believability \\
customer & (2) Honesty \\
(7) Credibility & (3) Reputation of service \\
(1) Appearance & (2) Tools or equipment used to provide the service \\
(11) Competence & (3) Availability of physical facilities \\
(12) Flexibility & (2) Eoliteness, respect and consideration \\
(10) Price & (1) Discountable for money \\
& (2) Valuable for money \\
& (1) Specificication and volume flexibility \\
&
\end{tabular}

Table 2. Sample demographic characteristics

\begin{tabular}{|c|c|c|c|c|c|}
\hline & $\mathrm{N}$ & $\%$ & & $\mathrm{~N}$ & $\%$ \\
\hline Age & & & Gender & & \\
\hline 15 to 25 & 6 & 15.8 & Male & 26 & 68.4 \\
\hline 25 to 35 & 21 & 55.3 & Female & 12 & 31.6 \\
\hline 35 to 45 & 8 & 21.1 & Education Level & & \\
\hline 45 to 55 & 3 & 7.9 & High School & 0 & 0 \\
\hline 55 and over & 0 & 0 & Diploma & 5 & 13.2 \\
\hline Marriage Status & & & Associates & 6 & 16.7 \\
\hline Single & 12 & 31.6 & Bachelors & 19 & 50 \\
\hline Married & 26 & 68.4 & Masters and higher & 8 & 21.1 \\
\hline Purpose of the Journey & & & Customers' Revenue (Rials) & & \\
\hline Job related & 24 & 63.2 & Less than 3000000 & 3 & 7.9 \\
\hline Entertainment & 13 & 34.2 & 3000000 to 5000000 & 6 & 15.8 \\
\hline Others & 1 & 2.6 & More than 5000000 & 29 & 74.4 \\
\hline
\end{tabular}


Table 3. Mean and Std. deviation values of the gaps of SQDs

\begin{tabular}{llllllll}
\hline No. & Item & Mean & $\begin{array}{l}\text { Std. } \\
\text { Deviation }\end{array}$ & No. & Item & Mean & $\begin{array}{l}\text { Std. } \\
\text { Deviation }\end{array}$ \\
\hline 1 & Reliability & 0.5684 & 0.5794 & 7 & Creditability & 0.2447 & 0.6845 \\
2 & Responsiveness & 0.4447 & 0.5631 & 8 & Tangibles & 0.4184 & 0.7436 \\
3 & Security and confidentiality & 0.3526 & 0.5316 & 9 & Courtesy & 0.4211 & 0.9410 \\
4 & Access and approachability & 0.4737 & 0.6571 & 10 & Price & 1.1447 & 1.0585 \\
5 & Communication & 0.2632 & 0.8522 & 11 & Competence & 0.6579 & 0.7453 \\
6 & Understanding the customer & 0.3684 & 0.8438 & 12 & Flexibility & 0.5132 & 0.7212 \\
\hline
\end{tabular}

Table 4. Two Tailed Pearson Correlation Test for SQDs gaps

\begin{tabular}{|c|c|c|c|c|c|c|c|c|c|c|c|c|c|}
\hline No. & $\begin{array}{l}\text { Service Quality } \\
\text { Dimensions }\end{array}$ & 1 & 2 & 3 & 4 & 5 & 6 & 7 & 8 & 9 & 10 & 11 & 12 \\
\hline 1 & Reliability & 1 & $0.409^{* *}$ & 0.128 & $0.363^{*}$ & 0.250 & $0.434^{* *}$ & $0.385^{* *}$ & $0.320^{*}$ & $0.383^{* *}$ & 0.043 & 0.171 & $0.392^{* *}$ \\
\hline 2 & Responsiveness & & 1 & 0.219 & $0.284^{*}$ & $0.499^{* *}$ & $0.394^{* *}$ & $0.478^{* *}$ & 0.163 & $0.479^{* *}$ & $0.272^{* *}$ & 0.269 & $0.498^{* *}$ \\
\hline 3 & $\begin{array}{l}\text { Security and } \\
\text { confidentiality }\end{array}$ & & & 1 & $0.317^{*}$ & 0.240 & 0.242 & $0.373^{*}$ & $0.336^{*}$ & -0.064 & 0.085 & 0.091 & 0.097 \\
\hline 4 & $\begin{array}{l}\text { Access and } \\
\text { approachability }\end{array}$ & & & & 1 & $0.339^{*}$ & $0.298^{* *}$ & $0.408^{* *}$ & 0.244 & 0.303 & $0.297^{*}$ & 0.229 & $0.314^{*}$ \\
\hline 5 & Communication & & & & & 1 & $0.397^{* *}$ & $0.556^{* *}$ & 0.225 & $0.600^{* *}$ & 0.196 & $0.422^{* *}$ & $0.511^{* *}$ \\
\hline 6 & $\begin{array}{l}\text { Understanding the } \\
\text { customer }\end{array}$ & & & & & & 1 & $0.551^{* *}$ & -.013 & 0.225 & -0.122 & 0.184 & 0.103 \\
\hline 7 & Creditability & & & & & & & 1 & $0.354^{*}$ & $0.442^{* *}$ & 0.187 & $0.465^{* *}$ & $0.429^{* *}$ \\
\hline 8 & Tangibles & & & & & & & & 1 & $0.276^{*}$ & $0.355^{*}$ & $0.548^{* *}$ & $0.304^{*}$ \\
\hline 9 & Courtesy & & & & & & & & & 1 & $0.371^{*}$ & $0.587^{* *}$ & $0.470^{* *}$ \\
\hline 10 & Price & & & & & & & & & & 1 & 0.253 & $0.431^{* *}$ \\
\hline 11 & Competence & & & & & & & & & & & 1 & $0.524^{* *}$ \\
\hline 12 & Flexibility & & & & & & & & & & & & 1 \\
\hline
\end{tabular}

${ }^{*}$ Significant at $0.05,{ }^{* *}$ Significant at 0.01 